\title{
Cyclin-Dependent Kinase Inhibitor 1C
}

National Cancer Institute

\section{Source}

National Cancer Institute. Cyclin-Dependent Kinase Inhibitor 1C. NCI Thesaurus. Code C17586.

Cyclin-dependent kinase inhibitor 1C (316 aa, 32 kDa) is encoded by the human CDKN1C gene. This protein is involved in the regulation of cell proliferation. 